ESTUDOS R:E?

\title{
Políticas de ações afirmativas e pobreza no Brasil
}

Sueli Menezes Pereira

Clarice Zientarski

\section{Resumo}

Questiona as políticas de ações afirmativas por cotas para ingresso no ensino superior e debate a questão social, considerando nossa formação como povo e as condições de desenvolvimento do País. Aborda a origem do problema a partir da história da colonização brasileira e analisa a situação da pobreza e as condições de exclusão do pobre diante dos direitos sociais, especialmente o direito à educação de qualidade, independentemente de raça ou gênero. Por fim, analisa a escola básica e seus resultados, evidenciando a educação básica de qualidade como verdadeira ação afirmativa.

Palavras-chave: ações afirmativas; pobreza; formação social; escola básica. 


\section{Abstract \\ Affirmative policies and poverty in Brazil}

The present work analyzes the affirmative actions regarding quotas, which enable access to high education, as well as it discusses the social question considering the formation and development model of Brazil. Through the Brazilian colonization history the article identifies the origin of the question and analyzes the poverty and exclusion conditions concerning the social rights, especially the right to education to any children not considering racial and genre aspects. Finally, it analyzes the basic education school and its results highlighting the basic education quality as a truly affirmative action.

Keywords: affirmative actions; poverty; social formation; basic education.

\section{Introdução}

O tema referente às políticas de ações afirmativas por meio de cotas nas universidades públicas tem sido o foco de muitos debates com posições que se destacam por seus argumentos, em geral contraditórios, sobre a aceitação dessas cotas, especialmente quando se referem à realidade do Brasil. Na perspectiva de levantar questionamentos sobre o assunto, este trabalho, de cunho teórico, pretende incrementar o debate existente no País sobre as ações afirmativas, tomando como base a origem desse movimento e a questão do multiculturalismo presente nas políticas. Participar do debate torna-se condição necessária, considerando-se a história de nossa formação sociopolítica e econômico-cultural e as características educacionais do Brasil atualmente.

Entende-se com Bergmann (1996) que realizar uma ação afirmativa implica planejar e atuar no sentido de promover a representação de certos tipos de pessoas, especialmente aquelas pertencentes a grupos que têm sido subordinados ou excluídos dos direitos sociais.

As ações afirmativas tiveram sua origem na década de 1940, na Índia, como medida assegurada na Constituição Federal do período, para garantir a reserva de vagas no ensino superior, no Parlamento e no funcionalismo público, aos membros da casta dos dalits ${ }^{1}$ ou "intocáveis". A Índia, portanto, é o país de mais longa experiência histórica com políticas de ação afirmativa, que começaram a ser implantadas ainda sob o domínio colonial inglês e depois foram ratificadas pela Constituição de 1947, no país já independente.

Tal como na Índia, ocorreram experiências semelhantes em outros países, como a Alemanha, a Nova Zelândia, a Malásia, a Austrália, a
${ }^{1}$ Dalits (impuros), ou seja, a "poeira sob os pés". Os dalits ou párias não pertencem às castas. São os chamados intocáveis (a quem Mahatma Gandhi deu o nome de harijan, "filhos de Deus"). São constituídos por aqueles (e seus descendentes) que violaram os códigos das castas a que inicialmente pertenciam. São considerados impuros e, por isso, ninguém ousa tocar-lhes. Ver SHAKTI, Deva. Disponível em http://deva-dani.blogspot. com/2009/02/dalits.html 
Nigéria, a África do Sul, entre outros. Na África, as políticas de ação afirmativa podem ser identificadas nos processos de independência dos países do Continente, assim como do Caribe e do Pacífico Sul, depois da Segunda Guerra Mundial (Wedderburn, 2005). Assegura Wedderburn que, com o propósito de colocar a população nativa em lugar dos europeus nos postos de comando da sociedade, países como Gana e Guiné adotaram políticas chamadas de "nativização" ou "indigenização", que consistiam na imposição, mediante decreto, de cotas e outras medidas específicas para a formação de um quadro administrativo autóctone.

$\mathrm{Na}$ América, as ações afirmativas foram implantadas na década de 1960, encabeçadas pelos Estados Unidos, cujo objetivo foi promover a igualdade entre os negros e os brancos norte-americanos. Foram originadas, portanto, de uma questão racial. Na sequência, as políticas de ações afirmativas foram adotadas em muitos países americanos, consideradas as diferenças culturais e econômicas de cada um, tais como Canadá, Cuba e Argentina. Nesses países, o objetivo comum foi oferecer a segmentos discriminados da sociedade tratamento diferenciado, como compensação pelas desvantagens originadas das condições sociais desiguais de vida.

Pode-se dizer com Weiden (2005), que ações afirmativas:

[...] são medidas especiais e temporárias, tomadas ou determinadas pelo Estado, espontânea ou compulsoriamente, com o objetivo de eliminar desigualdades historicamente acumuladas, garantindo a igualdade de oportunidades e tratamento, bem como de compensar perdas provocadas pela discriminação e marginalização, decorrentes de motivos raciais, étnicos, religiosos, de gênero e outros (Weiden, 2005).

Nesse cenário, é importante levantar alguns questionamentos: as políticas de ações afirmativas no Brasil deverão centrar sua ação no ensino superior ou na problemática que envolve a base da escolaridade, que se caracteriza pela exclusão da maioria da população ao direito por uma educação básica de qualidade, o que acontece em nossa realidade desde o início de nossa história política? Estarão as políticas de cotas raciais no ensino superior, efetivamente, respondendo aos problemas reais de escolaridade, que se encontram na questão social evidenciada pela pobreza e pela falta de oportunidades a uma escola básica de qualidade? Estariam as ações afirmativas invertendo as prioridades educacionais do País, pela preocupação com as consequências, sem um maior enfoque nas causas do problema?

Esses questionamentos se fazem necessários, considerando que as propostas de ações afirmativas têm colocado ênfase maior nas questões de raça e de gênero. Isso origina uma aparente democratização das oportunidades educacionais, não evocando a condição socioeconômica das classes excluídas, situação essa que entendemos ser a centralidade da problemática em questão. Nesse particular, evidencia-se a questão da pobreza, da discriminação e da exclusão, a que nos têm submetido os interesses do capital, com seus reflexos nos resultados educacionais, a partir do início da escolarização. 
Temos de considerar que até trinta ou quarenta anos atrás as prioridades do Brasil estavam ligadas ao desenvolvimento econômico, à modernização do Estado, à participação política, à democracia e à mobilidade social. Hoje, o tema da pobreza aparece em primeiro plano (Schwartzman, 2004). Não é um problema exclusivo do Brasil ou dos países do Terceiro Mundo, mas uma realidade que vem condicionando alternativas de políticas sociais e, nestas, as educacionais.

Ao olharmos para a situação mundial, podemos afirmar com Lucci (2003) que o problema da pobreza tornou-se planetário, o que se constitui uma das grandes contradições do mundo contemporâneo, considerando que no Relatório 2000/2001 sobre o Desenvolvimento Mundial, dedicado ao tema do combate à pobreza, observa-se, paradoxalmente, que nunca se produziu tanto e em nenhum momento se aplicou tanta ciência para a produção de bens e serviços como hoje e, apesar disso, 2,8 bilhões de pessoas, ou seja, quase metade da população mundial, vive com menos de 2 dólares por dia. Em nosso país, o Banco Mundial (Bird), que trabalha com dados oficiais do Instituto de Pesquisa Econômica Aplicada (Ipea), estimava em 2008 o número de pobres em 11,35 milhões, dos quais 3,12 milhões eram indigentes.

Como pobres, conforme o Ipea, definem-se todas as pessoas com renda per capita igual ou inferior a meio salário mínimo ( $\mathrm{R}$ \$272,50). Da mesma forma, são consideradas pessoas em condição de indigência aquelas com renda per capita igual ou inferior a um quarto do salário mínimo.

Isso considerado, o presente texto levanta questões, abordando, inicialmente, a origem do problema na história da colonização do país no qual se originaram as políticas de ações afirmativas na América (Estados Unidos) e na história da colonização do nosso país, em uma perspectiva comparada, que enfoca os diferentes interesses dos países colonizadores e suas consequências na formação socioeconômica dos Estados Unidos e do Brasil.

Essa abordagem implica, de maneira geral, analisar as similaridades históricas compartilhadas por Estados Unidos e Brasil, as maiores colônias europeias a utilizar extensamente o trabalho escravo de africanos e seus descendentes no Novo Mundo, bem como a grande influência da cultura norte-americana, que é particularmente forte nos países do continente americano.

Como influência maior da cultura norte-americana, aparece com visibilidade a cultura negra dos Estados Unidos, a qual acumula um passado rico de lutas contra a discriminação racial. Ou seja, devido a razões de poder imperial e de protagonismo histórico, o movimento negro americano e suas formas de luta, mobilização e conquista tornaram-se referenciais importantes para o movimento negro em todos os países que sofreram discriminação racial e exploração do trabalho escravo, como é o caso do Brasil.

Num segundo momento, o trabalho analisa a situação do Brasil, enfocando a questão da pobreza e as condições de exclusão do pobre frente aos direitos sociais. Nessa ótica, a atenção principal recai sobre a 
escola básica e sua importância para as políticas públicas em nosso País. Por fim, em um terceiro momento, o trabalho analisa a situação da escola básica e seus resultados, que se caracterizam pela exclusão social, tendo como um de seus fatores a falta de escola para todos, assim como a falta de uma escola de qualidade.

\section{Escravismo e capitalismo: revendo a história da colonização nos Estados Unidos e no Brasil}

A solução para a questão racial nos Estados Unidos buscou formas de ação afirmativa mediante programas específicos para o negro, diferentemente das ações afirmativas para mulheres, índios, deficientes físicos e imigrantes (Kaufmann, 2007). Isso nos leva a concluir que o problema central dessas ações surgiu da questão racial, especificamente em relação ao negro, devido à política de segregação racial implantada naquele país.

Nos países do Terceiro Mundo, observa-se que essas políticas têm sido adotadas como forma de resolver os problemas educacionais, copiando as soluções dos países dominantes do capitalismo central, sem considerar as diferenças estruturais e culturais entre o país que inspirou essas políticas na América do Norte e os países da América Latina, que hoje buscam as mesmas alternativas, apesar das diferenças históricas e do atual contexto, especialmente o Brasil.

A nossa história de escravidão e a miscigenação de raças (brancos, índios, negros), que se deu a partir da colonização, poderia justificar a busca de alternativas norte-americanas para nossa realidade, fazendo adaptações de iniciativas e soluções, o que facilitaria medidas afirmativas sobre a questão racial no País. Diante disso, há de se considerar os diferentes contextos entre os dois países, apesar da produção acadêmica e jurídica sobre o assunto. Torna-se necessário, portanto, identificar argumentos brasileiros com a produção externa, "como se os programas positivos fossem os resultados de uma evolução lógica da concretização do princípio da igualdade, partindo do Estado Liberal ao surgimento do Welfare State" (Kaufmann, 2007, p. 2).

A defesa da necessidade de cópia das soluções adotadas nos Estados Unidos tem como argumento a ideia de que o Brasil "faz de conta" que não vê o racismo, porque este vem sendo camuflado, escondido, enquanto os EUA o assumem publicamente com políticas de todas as ordens, especialmente as de caráter educativo, o que deve ser mais bem analisado, considerando que não é apenas a forma como se encara o racismo no país que faz a diferença, a começar pelas condições históricas dos povos colonizadores do Brasil e dos Estados Unidos - Portugal e Inglaterra, respectivamente.

A história da colonização dos Estados Unidos pela Inglaterra e do Brasil por Portugal traz, desde a origem, grande diversidade cultural, evidenciando os enfoques distintos de desenvolvimento dos dois países, considerados os interesses econômicos que pautaram as ações dos colonizadores. 
Com a descoberta da América, afloram os desejos de expansão imperial, militar, política e econômica. Começa a colonização.

A acumulação primitiva se processa com uma crueldade estarrecedora. O roubo, o saque, a pirataria, a matança de índios indefesos, o rapto e a escravidão negra tornaram-se um sistema regular e rotineiro de comércio e a base de acumulação capitalista (Basbaum, 1975, p. 41).

Para Basbaum (1975, p. 42), a história da Inglaterra, a partir do século 16, "deixa de ser a história de seus reis para ser a história de seu comércio e de sua indústria". Nesse processo, os navios ingleses e seus piratas dominam os mares com proteção real.

Protegida por rigorosas leis que visavam resguardar sua indústria e seu mercado interno, a Inglaterra desejava não somente as riquezas do Novo Mundo, que assombravam a Europa, por meio de Portugal e Espanha, mas promover a expulsão dos camponeses expropriados, que se tornaram uma massa de mendigos, vagabundos e aventureiros em suas cidades. Era preciso buscar alternativas para os problemas sociais que se apresentavam, assim como criar novos mercados. É nesse clima, associado ao espírito expansionista, que se dá a colonização e, nesse processo, a colonização da América do Norte.

A colonização da América não visava apenas libertar-se de um excesso de gente capaz de provocar perigosas agitações na Inglaterra, nem mesmo apenas um asilo inesperado para os descontentes religiosos ou políticos de toda a espécie [...]. Era também uma possibilidade de criar novos mercados para os produtos ingleses (Basbaum, 1975, p. 50).

No Brasil, a situação diverge, visto que o interesse de Portugal na colônia, na condição de metrópole colonizadora, não se calcava em um desenvolvimento econômico e cultural próprio e sim em "sua incorporação no mercado mundial" (Sodré, 1977, p. 4). Para tanto, promoveu a colonização apenas com homens brancos, ensejando "o caldeamento dos portugueses com índias e escravas negras" (Kaufmann, 2007, p. 3), favorecendo, desse modo, a formação de um povo altamente miscigenado, como é o brasileiro.

Diferentemente, ao colonizar os Estados Unidos, a Inglaterra teve o intuito de povoar a terra, originando núcleos familiares somente de raça branca. A isso se alia o desenvolvimento da manufatura, que ocorria na Inglaterra, e o fortalecimento do protestantismo, promovendo "a ética do trabalho e a recompensa do esforço individual" (Kaufmann, 2007, p. 3) e evidenciando a Inglaterra, como diz Basbaum (1975), como potência mercantil que repercutiu na era moderna.

Desde o século 16, a Inglaterra transforma-se de país feudal em país mercantilista e burguês, tornando-se a maior potência capitalista da época. Isso se dá pela expropriação da terra, que levou os camponeses para a cidade e formou o maior exército de reserva de mão de obra imaginável, tornando o sistema artesanal, até então predominante, sem sentido. Em seu lugar, a produção da manufatura em bases capitalistas encaminha os artesãos para as fábricas. 
A reforma da Igreja deu novo impulso a esse processo de expropriação, no momento em que a Igreja, grande proprietária de terras com uma organização de produção feudal, perde suas terras, e seus moradores são atirados ao proletariado.

Portugal, por sua vez, apresenta uma realidade bem diferenciada. O domínio do rei sobre as terras, como diz Azevedo (apud Basbaum, 1975, p. 43), era o de "uma monarquia tipicamente agrária". Indústrias não havia, e a pobreza era endêmica, em evidente contraste com o luxo da Corte. No século 15, a descoberta do caminho marítimo das Índias representou para Portugal uma "fonte de maravilhas e riquezas sem fim, o ouro, as especiarias, os escravos" (Basbaum, 1975, p. 45). Naquele período, Portugal já possuía um grande contingente de negros, pois, como informa o autor, só em Lisboa, 10\% da população eram de negros.

Isso repercute em nosso país, visto que os portugueses, já convivendo com negros antes da descoberta do Brasil, evidenciam Portugal como um país de forte miscigenação racial e faz do Brasil, como diz Sodré (1977), um país de "cultura transplantada". O mesmo não acontecia na Inglaterra, que só se utilizou da mão de obra escrava, negra, a partir do século 18 , uma mão de obra que nunca foi considerada efetiva para os ingleses. O maior interesse pelos negros era devido ao tráfico, "devido aos vultosos ganhos comerciais que se originavam com a magnífica frota de navios negreiros", como explica Kaufmann (2007, p. 3).

Esses fatos evidenciam que a escravização assume papel diferente na colonização dos Estados Unidos e do Brasil. Enquanto no Brasil o escravo chegava nos primórdios da colonização e se constituía mão de obra exclusiva para uma produção agrária rudimentar, nos Estados Unidos, o escravo chegou cem anos depois da colonização, que foi feita pelo branco, a partir da divisão da terra.

Há que se considerar, como fator relevante, que nos Estados Unidos os escravos tiveram pouca importância para a economia como um todo, especialmente se lançamos um olhar burguês, visto que, salvo em algumas regiões produtoras de algodão, onde a mão de obra escrava foi utilizada, esta assumiu posição secundária. Isso é o que indica Basbaum (1975), considerando o tipo de economia na qual assumia prioridade o trabalho livre, base da produção manufatureira. Nesse contexto, "o escravo era um elemento negativo e mais ainda do ponto de vista da formação de uma mentalidade artesã, burguesa ou proletária" (Basbaum, 1975, p. 93).

Diferentemente, no Brasil, o escravo se constituiu a base estrutural da economia agrária, mas dificilmente se poderia dizer que a escravização contribuiu para o desenvolvimento econômico do País. Essa afirmação se apoia no fato de que, sendo a mão de obra escrava, e sendo o escravo excluído dos direitos sociais, assim como da remuneração do trabalho, esse tipo de produção não contribuiu para a formação de uma estrutura de acordo com o modelo capitalista de acumulação presente nos países industrializados.

A exploração do trabalho escravo beneficiou grandes proprietários de terras que se utilizaram desse modo de produção, arcaico, para 
o enriquecimento pessoal. As consequências disso consolidaram a desigualdade social em termos econômicos, políticos, educacionais, o que explica as grandes disparidades regionais ainda hoje no Brasil.

Tem-se de levar em conta que até 1789 a população brasileira totalizava 3 milhões e 250 mil pessoas, das quais 1 milhão e 582 mil eram escravos, negros e pardos. Computa-se, ainda, 406 mil negros livres, 250 mil índios e 1 milhão e 10 mil indivíduos brancos que, na sua maioria, eram pobres, o que não favorecia a formação de uma classe consumidora (Basbaum, 1975).

Nesse quadro, os escravos totalizavam mais de 50\% da população, que por 400 anos foi excluída de qualquer direito social e, como tal, não fomentou a formação de um mercado interno no País, ficando este à mercê das determinações do mercado internacional. Isso indica que o Brasil, além de não se organizar para integrar-se ao mundo desenvolvido, industrial, manteve, sem nenhum questionamento, uma população pobre de diferentes raças, sendo o negro o de maior expressão numérica. Pode-se dizer com Basbaum (1975, p. 93) que "a escravização (como modo de produção) é [...] uma das causas de nosso atraso", tanto do ponto de vista da ausência de consumo, como da formação de uma mentalidade artesã, burguesa ou proletária.

Havia no Brasil, no entanto, a probabilidade de compra da liberdade pelo próprio escravo, ou de libertação espontânea por parte dos senhores, ${ }^{2}$ o que se evidencia nos dados apontados pelo número de negros livres, enquanto nos Estados Unidos existiam leis que impediam qualquer possibilidade de existência de negros livres.

As diferenças são muitas, incluindo o processo de libertação dos escravos. Enquanto a abolição da escravatura no Brasil foi precedida por um intenso e pacífico movimento nacionalista, apesar dos interesses do mercado internacional, a abolição nos Estados Unidos foi precedida da mais violenta guerra civil, do que decorreu uma matança indiscriminada dos negros pelos brancos.

Essas são diferenças significativas, que evidenciam o caráter racial da colonização nos dois países. As diferenças manifestam-se na forma dos povoamentos, dos interesses econômicos e religiosos, no emprego da mão de obra escrava, na existência, ou não, de miscigenação entre as raças, nas causas da abolição, no tratamento dado ao negro depois da abolição, na questão da divisão da terra e do próprio desenvolvimento de cada país.

Nessa conjuntura se desenvolve o período de colonização em ambos os países, que apresenta diferenças em seu próprio processo de independência. No Brasil, de acordo com Mota e Novais (1996), o Estado metropolitano é dividido na relação entre o Estado e a sociedade, visto que há um tipo de relação na colônia e outro na metrópole. Na colônia, a classe dominante não é a elite dirigente.

A classe dominante na colônia é o senhoriato, os donos de terra e de gentes. Nesse contexto, a Independência busca, de certa forma, ajustar a sociedade ao Estado, e a Nação trabalha para fazer esse ajuste de modo a defender as ideias propostas. No entanto, isso não provoca mudanças
2 Os escravos, quando libertos, não encontravam nenhuma resistência social organizada. Calcula-se que, em 1887, 5\% da população brasileira era escrava, sendo $90 \%$ dos escravos negros livres (Kaufmann, 2007). 
sociais e, além do mais, para os negros e os índios, não havia diferença entre ser governado pelo senhoriato ou pela metrópole (Mota; Novais, 1996).

Além disso, a sociedade brasileira manteve sua estrutura política, econômica e social praticamente intacta, e a unidade do território não se alterou em relação ao período colonial, porque o processo de independência foi empreendido por quem já estava no poder (Mota; Novais, 1996).

Nos EUA, o processo de independência teve características próprias. Nesse país, os colonos participaram dos debates em busca de alternativas para acabar com os abusos cometidos pelos ingleses. Essas ações ficaram explícitas nos congressos realizados na Califórnia, nos quais se constatou que os colonos lutaram para ter o direito de participar da vida política da colônia (Driver, 2006).

Como a Inglaterra não aceitou a independência de suas colônias e declarou guerra, os EUA enfrentaram seu colonizador. A Guerra de Independência, que ocorreu entre 1776 e 1783, foi vencida pelos EUA com o apoio da França e da Espanha. Apesar dessas diferenças, não se pode ignorar que os processos que conduziram à independência das colônias foram parte integrante da decadência do Antigo Regime e resultante da difusão do liberalismo econômico. Nenhum dos movimentos, no entanto, contribuiu para a melhoria de condições dos negros. Ao contrário, a discriminação e a pobreza da população negra continuaram.

Nos Estados Unidos, em decorrência do acirrado ódio racial ao negro, a segregação foi decretada pelo Estado como medida legal e legítima, com o consequente separatismo instituído por políticas públicas traduzidas em leis, as quais proibiam os negros de frequentar escolas, igrejas, banheiros públicos, parques, praias, hospitais, ou qualquer local público frequentado pelos brancos. Além disso, os negros eram proibidos de ter propriedades, de trabalhar em qualquer profissão, de votar, de serem testemunhas, de dirigirem nas mesmas estradas, situação que ocasionou "o movimento dos negros pelo fim da segregação racial nos EUA nas décadas de 1950 e 1960 e popularizou um conceito jurídico original: o da ação afirmativa ou discriminação positiva" (Tragtenberg, 2002, p. 2).

A segregação racial nos Estados Unidos causou prejuízos à própria formação de mão de obra compatível com as necessidades do capital. Essa situação levou empresas e Estado a buscarem a aplicação das leis dos direitos civis e políticos, visando reduzir a discriminação racial, mas, principalmente, os efeitos dela sobre a sociedade e a economia.

É nesse contexto que ocorre uma mudança de postura do Estado, na qual a questão educacional toma forma a partir de 1961 pelo sistema de cotas. Os resultados foram quase uniformemente desastrosos. Admitidos de forma condescendente, por critérios menos exigentes do que os dos demais, os estudantes negros ficaram isolados dentro das universidades, seguindo currículos de qualidade acadêmica duvidosa, que pouco lhes servia na vida profissional posterior. Era um sistema que discriminava alunos brancos, que muitas vezes não eram admitidos nas universidades para dar lugar a negros menos qualificados e, por isso, a Suprema Corte 
Americana julgou o sistema de cotas inconstitucional (Schwartzman, 1987; Martins, 2008).

São questões que, necessariamente, fazem a diferença e não permitem pensar que soluções adotadas nos Estados Unidos possam ser transpostas para o Brasil. Trata-se, no caso do Brasil, de um país dependente do capitalismo central, ainda carente de avanços na área educacional para todos os níveis, que vão além das questões de raça ou de gênero, embora estas não possam ser desprezadas.

A Convenção Internacional sobre a Eliminação de todas as Formas de Discriminação Racial, da Organização das Nações Unidas (ONU), da qual o Brasil é signatário desde 1967, estabeleceu a necessidade de aplicar ações afirmativas como forma de promoção da igualdade, para a inclusão de grupos étnicos historicamente excluídos do processo de desenvolvimento social (Martins, 2008). É o que veremos a seguir.

\section{Ações afirmativas no Brasil}

A Constituição Federal do Brasil de 1988, Art. 3º, IV, enfatiza "a promoção do bem de todos, sem preconceitos de origem, raça, sexo, cor, idade e quaisquer outras formas de discriminação". Essa determinação legal apontou para a necessidade de o País adotar a política de ação afirmativa que, conforme Martins (2008), tem sua maior ênfase na década de 1990: a Lei no 8.112/90 (Artigo $5^{\circ}, \S 2^{\circ}$ ), que reserva vagas, no percentual de $20 \%$, para deficientes físicos habilitados a cargos públicos; para empresas, que devem oferecer vagas para deficientes (Lei no 8.213/91, Art. 93, que fixa para deficientes a cota mínima de $2 \%$ e máxima de 5\%), e a Lei no 9.504/97, Art. 10, § 3, que reserva para as mulheres percentual para participarem como candidatas de partidos políticos, evidenciando que em nosso País o sistema de cotas de vagas não tinha como proposta a inclusão racial.

Por sua vez, no período do golpe militar (1964-1985), foi criado um sistema de cotas na educação que visava a privilégios de classe que não necessariamente a excluída socialmente. Foi o caso da chamada "lei do boi", Lei no 5.465/68, ${ }^{3}$ que criou a reserva de vagas (50\%) "para candidatos agricultores ou filhos destes, proprietários ou não de terras", que residissem com suas famílias na zona rural, e 30\% para agricultores ou filhos destes, proprietários ou não de terras, que residissem em cidades ou vilas que não possuíssem estabelecimentos de ensino médio, nos cursos de graduação em Agricultura e Veterinária. Por essa lei, manipulada nos seus reais objetivos, bastava o título de propriedade para garantir vaga e, com isso, a lei acabou apenas por favorecer a elite rural brasileira.

Nessa mesma perspectiva, a política de ação afirmativa é tratada em muitas leis, sendo a Consolidação das Leis do Trabalho (CLT) uma das mais conhecidas e abrangentes. Por essa lei, fica garantido o emprego para brasileiros, na proporção de dois terços em empresas individuais ou coletivas (podendo, neste caso, um terço ser destinado a estrangeiros),
${ }^{3}$ Lei $n^{\circ} 5.465$, de 3/7/1968 - Lei Ordinária, conhecida como "Lei do boi". Disponível em: http:// www6.senado.gov.br/sicon/ListaReferencias.action?codigoBase $=$ 2\&codigoDocumento $=1939205$ Acesso em: 12/3/2010 
assim como visa corrigir distorções responsáveis pela desigualdade de acesso da mulher ao mundo do trabalho.

Como se observa, o Brasil vem assumindo políticas de ações afirmativas, tendo um histórico que não prioriza as necessidades sociais na sua íntegra. Em 1999, a questão racial integra as políticas educacionais mediante o Projeto de Lei $n^{\circ}$ 73/99, pelo qual fica instituído o Sistema Especial de Reserva de Vagas para estudantes egressos de escolas públicas, em especial negros e indígenas, nas instituições públicas federais de educação superior.

Mediante esse projeto de lei, o Brasil busca resgatar uma dívida histórica marcadamente com os negros e índios, garantindo-lhes acesso ao ensino superior, o que nos leva ao seguinte questionamento: como fica a garantia de direitos ao ensino superior para a totalidade dos excluídos da sociedade, tendo como referência a exclusão a partir da escola básica? Como é tratada a questão da pobreza e do fracasso educacional brasileiro, tão evidenciados em relatórios de órgãos governamentais nacionais e internacionais, nas políticas de ações afirmativas?

Pensa-se que as políticas educacionais atuais buscam responder a essas questões, quando definem "o direito à educação, entendido como direito inalienável do ser humano [...]. A educação permite o exercício dos direitos civis, políticos, sociais e do direito à diferença, sendo ela mesma também um direito social" (Resolução CNE/CEB n 7/2010, Art. 5).

Por essa resolução, a educação fica comprometida com a igualdade do acesso e empenhada em garantir esse acesso aos grupos da população em desvantagem na sociedade.

\footnotetext{
A equidade alude à importância de tratar de forma diferenciada o que se apresenta como desigual no ponto de partida, com vistas a obter desenvolvimento e aprendizagem equiparáveis, assegurando a todos a igualdade de direito à educação. Na perspectiva de contribuir para a erradicação da pobreza e das desigualdades, a equidade requer que sejam oferecidos mais recursos e melhores condições às escolas menos providas e aos alunos que deles mais necessitem. Ao lado das políticas universais, dirigidas a todos sem requisito de seleção, é preciso, também, sustentar políticas reparadoras que assegurem maior apoio aos diferentes grupos sociais em desvantagem (Resolução CNE/CEB n ${ }^{\circ}$ 7/2010, Art. 50, § $3^{\circ}$, III).
}

O debate está em aberto e tem despertado fortes reações, principalmente nos setores que tradicionalmente são beneficiados pela estrutura desigual.

\section{Ações afirmativas para combater o racismo e a pobreza?}

Em agosto de 2001, ocorreu em Durban (África do Sul), a "3a Conferência Internacional de Combate ao Racismo, Discriminação Racial, Xenofobia e Formas Correlatas de Intolerância", promovida pela ONU, com intensa participação de entidades do movimento negro brasileiro. Nesse 
evento, a delegação brasileira levou propostas avançadas para lidar com os efeitos do racismo no Brasil, que, na época, apresentava, na totalidade, uma população negra de $45 \%$ (5\% de pretos e $40 \%$ de pardos, segundo a Pnad/IBGE de 1999).

Atualmente, de acordo com a Pesquisa Nacional por Amostra de Domicílio (Pnad), Censo 2010, o Brasil conta com uma população de 190.732.694 habitantes, dos quais 42,6\% são pardos e 6,9\% são negros, o que totaliza $49,5 \%$, frente a $49,7 \%$ de brancos, 0,3\% de indígenas e 0,5 de amarelos (Pnad, 2006), ${ }^{4}$ dados que, de certa forma, confirmam os estudos de Estronioli, realizados em 2010, quanto à proporção do crescimento da população negra e parda no País, diante do número de brancos, amarelos e indígenas.

Entre as propostas apresentadas, está a criação de cotas para os negros entrarem nas universidades públicas, considerando a proposição da Conferência de Durban, que colocou na ordem do dia a questão do racismo e como combatê-lo.

Em consequência disso, o Brasil teve como um dos resultados visíveis a aprovação de cotas de 40\% para negros nas universidades estaduais do Rio de Janeiro - Universidade Estadual do Rio de Janeiro (Uerj) e Universidade Estadual do Norte Fluminense (Uenf), em 9 de outubro de 2001 (Tragtemberg, 2002), iniciativa que foi sendo assumida por outras instituições de ensino superior nos demais Estados do Brasil, mas que é uma solução que não considera a exclusão da maioria pobre, independentemente da raça e das oportunidades educacionais, a partir da base da escolarização.

Apesar dos dados que indicam a alta percentagem de pobres, há dados da Fundação Getúlio Vargas que informam sobre a redução da pobreza no País. Diz o jornal O Tempo, de 2 de dezembro de 2005, que "a pobreza atingiu seu patamar mais baixo desde 1992", passando de 35\%, em 1992, para 25\%, em 2004. O fenômeno se explica, conforme o jornal mencionado, pelo crescimento da economia conjugado à ascensão social de parte da população contemplada com mais empregos, mais escolarização e acesso aos programas assistenciais do governo.

O significativo esforço empreendido atualmente para reduzir a pobreza, no entanto, são medidas insuficientes para equalizar o problema das enormes diferenciações sociais, considerando que ainda convivemos em pleno século $21 \mathrm{com} \mathrm{1/4} \mathrm{da} \mathrm{população} \mathrm{em} \mathrm{estado} \mathrm{de} \mathrm{extrema} \mathrm{pobreza.}$

O Brasil tem sofrido picos de crescimento econômico. De acordo com Pastore, Zylberstajn e Pagotto (1983), há, pelos dados estatísticos, um crescimento econômico relevante entre as décadas de 1950 e 1980, o que não evidenciou, no entanto, uma diminuição do nível de pobreza que maltrata o País, desde os seus primórdios. É um crescimento que não alimentou esperanças aos favelados, desempregados, aposentados, marginalizados, às prostitutas e aos menores abandonados nos labirintos da vida.

Os autores citados discutem ainda a situação de pobreza em que vivem os assalariados no Brasil, pois um grande percentual sobrevive bem abaixo do mínimo delimitado pela Organização das Nações Unidas
${ }^{4}$ Dados do Censo 2010. Disponível em: http://www.suapesquisa. com/geografia/populacao_brasileira.htm 
(ONU). Isso não diz respeito somente ao setor industrial privado, mas aos próprios governos estaduais, que remuneram mal seu pessoal, girando em torno de um a meio salário mínimo legal, quando o mínimo estipulado pelo Departamento Intersindical de Estatística e Estudos Socioeconômicos (Dieese) é três vezes o mínimo oficial.

No período estudado pelos autores, evidencia-se uma redução maior da pobreza na década de 1960 a 1970. Contudo, observou-se que isso só ocorreu devido à implantação das horas trabalhadas pelo operário envolvido e, até mesmo, à participação da mulher no mundo do trabalho, o que significa dizer que essa pequena redução no nível de pobreza, constatada pelos pesquisadores, não significa uma diminuição da pobreza, mas maior exploração do trabalhador, com o objetivo de a espoliação ser maior. A jornada de trabalho aumentou consideravelmente, assim como o exército industrial de reservas, com a participação das mulheres, independentemente de raça, que se sujeitaram a salários de miséria para incrementar o rendimento familiar.

No Brasil, a pobreza é maior nas regiões mais periféricas, como é o caso do Nordeste, Norte e outras regiões dessa mesma estrutura, que não foram beneficiadas pelos investimentos diretos injetados na Nação naquele período, além das condições históricas presentes desde o processo de colonização.

As fontes principais da pobreza nacional estão principalmente na má distribuição de renda, tendo em vista que o afunilamento na posse da renda nacional é visível. A década de 1980 foi pródiga nos arrochos salariais pelos quais passou a classe trabalhadora do País, impostos especialmente por decretos governamentais que tinham um único objetivo: o de tornar a classe produtiva mais pobre, em favor da classe improdutiva, tendo como consequência os direitos sociais reduzidos e, nestes, uma redução da quantidade e da qualidade no processo educacional brasileiro, entre outros serviços sociais.

Dizem os autores:

O Brasil é um país pobre; não vale apenas querer aparecer no cenário internacional como uma potência mundial, se a economia interna não caminha bem, nem tampouco há perspectiva de um desenvolvimento que leve a nação a ter um bem-estar condigno com o esforço de seus filhos que tanto lutam para crescerem bem (Pastore; Zylberstajn; Pagotto, 1983, p. 41).

Salles (2008), ao analisar os dados do Ipea sobre o Mapa brasileiro da pobreza, entre 1996 e 2006, diz que, embora o total de pobres tenha diminuído em 32,7\% da população, ainda são os negros e os pardos os mais afetados pela pobreza, especialmente na região Nordeste.

A população negra, que em 1996 tinha 46,7\% dos indivíduos vivendo na pobreza, apresentou uma queda de 13,5\%. Em 2006, 33,2\% (ou cerca de um terço) dos negros eram pobres. Em números absolutos, a mudança não parece tão significativa, já que mais de 30 milhões de pessoas se mantiveram em condições de pobreza. Isso porque a população negra também cresceu (Salles, 2008). 
Tomando esse quadro como referência, urge uma política de elevação da qualidade da saúde e da educação pública básica em um contexto de pobreza, considerando que a condição de vida oferecida pelos serviços sociais de melhor qualidade permite que os pobres de todas as raças entrem na Universidade e nela permaneçam. A política de cotas, ao contrário, se faz demagógica ao permitir que parte dos negros e dos demais excluídos sociais entrem nas universidades, mas, devido a toda uma conjunção de fatores, não se formem, ou, formados, fiquem alijados do mercado de trabalho, salvo raríssimas exceções.

Nesse caso, "ação afirmativa" é o mecanismo de inclusão das minorias em espaços públicos ou privados por meio de cotas, consistindo em uma via de mão dupla, no instante em que determina, necessariamente, a exclusão de membros pertencentes a grupos não minoritários, o que leva a um questionamento importante, visto que tal exclusão poderia afrontar o princípio da igualdade formal, ou seja, questionar se, por via oblíqua, geraria efeitos de discriminação reversa (Silva, 2002).

Isso considerado, não há como discordar de Tragtenberg (2002), quando destaca a importância de os brancos brasileiros perceberem que o problema dos negros e a discriminação racial e social por estes sofrida não são somente problemas deles. É um aspecto da injustiça reinante no Brasil, assim como são o da fome e o da pobreza em geral. Nesse cenário, uma crítica muito difundida no ideário progressista sobre a questão é que realmente os negros são desfavorecidos desde a escola básica.

Os negros são desfavorecidos por serem pobres e negros e não apenas por serem negros, assim como os brancos pobres e os pardos pobres, que ocupam a maior parcela da população do Brasil, evidenciando a imensa desigualdade social no País, sendo a educação básica um fator coadjuvante relevante nessa exclusão. Isso requer posicionamento e ações efetivas de brancos e negros no sentido do problema da exclusão ser enfrentado com vistas a soluções satisfatórias.

Ponderando com Soares e Alves (2003, p. 8):

A influência da posição social individual é reconhecida, pelo menos, desde a publicação do relatório Coleman, nos anos 1960 (Coleman et al., 1966). O nível socioeconômico do aluno é, sabidamente, o fator com maior impacto nos resultados escolares de alunos. Esse é um constrangimento real, extraescolar, que pode ajudar ou dificultar o aprendizado do aluno e que afeta diretamente o funcionamento e a organização das escolas e das salas de aula. Diminuir as diferenças entre a condição socioeconômica e cultural dos alunos de um sistema de ensino por meio de políticas sociais terá impacto nos resultados cognitivos dos alunos.

Ao vermos por essa ótica, compreendemos a educação básica de qualidade como o fator preponderante para evitar as discriminações e as ações afirmativas que se identificam com um multiculturalismo compreendido como um fenômeno "da inteligência acadêmica oficial dos EUA e outros órgãos formuladores de ideologias do aparato estatal deste país" 
(Bonfim, 2007, p. 3), com seus intelectuais que Gramsci denominaria de "intelectuais orgânicos da classe dominante". Para Bonfim (2007),

O multiculturalismo passou a ser a tábua de salvação, no alfa e no ômega do pensamento político. A ideologia de uma era sem ideologia, para grande parte da intelectualidade norte-americana. Porque o grande capital permaneceu, como sempre, reciclando-se, reatualizando seu discurso com o objetivo expansionista e do lucro sem limites (Bonfim, 2007, p. 4).

Segundo essa visão, no contexto multicultural, o segregacionismo racial continua, sob a forma de um discurso social que, aparentemente, oportuniza situação de igualdade, contudo, mediante novas formas de discriminação e, neste caso, a cota racial é forma de discriminação imposta pela lei, como nos diz Martins (2008).

Resolver o problema da exclusão mediante ações afirmativas por discriminação de raça e de gênero não é a solução que compreendemos para o nosso país. São ações paliativas, compensatórias e imediatistas que camuflam o problema. A solução poderia estar calcada em ações afirmativas por meio de políticas sociais em todas as áreas e, nestas, a educação de base voltada para a equidade e a qualidade, questões que se tornam complexas quando analisadas em nosso contexto de diferenciação social tão grande.

A discussão não pode ficar limitada ao problema do ingresso dos negros e dos afrodescendentes no ensino superior, ao processo de fragmentação e de reificação que as relações sociais de uma organização social capitalista impõem. Segundo Atílio Borón, "não se trata, em consequência, de suprimir ou negar a existência do 'diverso', para utilizar uma palavra muito em voga, da particularidade - e sim de procurar os termos exatos do seu relacionamento com a totalidade" (Borón, 1998, p. 5). Nesse aspecto, ao ser uma categoria oriunda do capitalismo, dever-se-ia considerar supérflua sua legitimação.

\section{Educação básica como direito social}

A universalização do ensino fundamental, agora em nove anos, a erradicação do analfabetismo, a ampliação das horas letivas, a democratização do acesso ao ensino médio, entre outras determinações da LDB/96 (Lei no 9.394/96), são propostas que têm merecido especial atenção nas políticas atuais de governo, mas ainda sem resultados que revertam o quadro do fracasso educacional brasileiro.

De acordo com Soares e Alves (2003), ao tratar das políticas educacionais atuais,

[...] criou-se no Brasil um grande sistema de ensino fundamental, que atende hoje a quase totalidade das crianças [...]. O ensino médio também caminha na direção da universalização, com cobertura atual de 85\% dos jovens de 15 a 17 anos. No entanto, a escola continua sendo um 
produto social desigualmente distribuído. Desigualdades no ingresso aos diferentes tipos e níveis de ensino persistem, ainda que se manifestem, hoje, de forma menos maciça e mais sutil. Essas desigualdades são moduladas por filtros socioeconômicos, raciais, de localização (urbana, rural) e por tipo de rede escolar (pública, particular). Há, portanto, dois problemas fundamentais: a qualidade do ensino de uma forma geral e as desigualdades entre os estratos sociais (Soares e Alves, 2003, p. 2).

Ninguém nega que o esforço para sanar esses problemas vem se dando pelo acesso ao ensino fundamental para todas as classes sociais. O problema fica, agora, centrado na qualidade, que, por ser complexa, exige esforço conjunto do Estado e da sociedade como comprometimento coletivo em busca de uma formação que atenda aos diferentes estratos sociais, sem discriminação de raça, sexo ou nível socioeconômico. Esse se torna o grande desafio a ser enfrentado por todos, de modo a preparar o cidadão para participar da vida social em todas as suas instâncias, de forma igualitária, seja ele branco, pardo, mulato, negro, amarelo, indígena. Com essa formulação, não há uma clara distinção entre "cor", "raça" ou "origem étnica". São todos brasileiros e merecedores do mesmo tratamento.

Nos estudos realizados por Soares e Alves (2003), por meio de dados do MEC/Inep/Saeb, considerando as desigualdades sociais entre os alunos com posição social mais baixa, a diferença entre os três grupos (brancos, pardos e negros) é mínima, enquanto nas posições mais privilegiadas o grau de proficiência entre os alunos se diferencia bastante. Nos grupos socialmente privilegiados, os brancos aparecem com melhor desempenho. Isso significa que para os alunos negros subirem na escala de prestígio social não implica a melhoria do nível de desempenho escolar na mesma proporção que ocorre com os alunos brancos, quando a diferença de nível socioeconômico favorece o branco.

Essa questão leva a outra altamente envolvida no que se refere à qualidade relacionada com a variação dos contextos escolares. No estudo realizado pelas autoras, a diferença de desempenho escolar observada entre alunos brancos, pardos e negros não encontra explicação somente na condição socioeconômica. Com base nos dados do Saeb, encontram-se evidências sobre a origem dessas diferenças de qualidade na proposta da escola, confirmando o que antes afirmamos sobre serem a própria instituição e os sistemas escolares coadjuvantes da exclusão.

Quanto a isto, dizem as autoras:

[...] sabemos que alunos de alta posição social, em média, têm melhor rendimento escolar e vão a escolas que oferecem bom ensino. Quando encontramos uma escola com alto desempenho, não sabemos se esse desempenho é alto porque seus alunos já eram bons antes ou porque a escola oferece, de fato, um bom ensino. Da mesma forma, a superioridade de um aluno deve-se a fatores socioeconômicos ou ao seu desempenho escolar prévio? (Soares; Alves, 2003, p. 7, grifo nosso).

A questão levantada por Soares e Alves (2003) encontra resposta na pesquisa realizada por Crespo e Gurovitz (2002), que afirmam ser a pobreza "privação de capacidades elementares", o que pode provocar 
${ }^{5}$ Dados obtidos no site http:/ ideb.inep. gov.br/Site/ Acesso em: 16/6/2008.

${ }^{6}$ Dados obtidos no site http:// ideb.inep. gov.br/Site/. Acesso em: 16/6/2008. "morte prematura, subnutrição considerável (especialmente de crianças), morbidez persistente, analfabetismo e outras deficiências". Para os autores, a pobreza pode também ser caracterizada como renda inferior a um patamar preestabelecido, pois uma renda baixa pode ser a razão primeira da privação de capacidades de uma pessoa, o que confirma a explicitação sobre pobreza e miséria já definidas neste trabalho.

Nessa perspectiva, estudos realizados entre diferentes raças mostram que a importância do professor no desempenho de sua função pedagógica junto a alunos pobres pode influenciar os resultados escolares, sem, no entanto, minimizar fatores de suas condições sociais. A afirmação a seguir confirma essa posição:

[...] poucos fatores têm impacto estatisticamente significativo. Ou seja, a maioria dos fatores associados a melhor desempenho afetam igualmente o conjunto dos alunos, independentemente da sua cor. Por exemplo, um professor que nutre altas expectativas em relação ao desempenho de seus alunos irá contribuir para o sucesso de todos os alunos, sem que isso necessariamente ajude a reduzir as diferenças iniciais entre eles (Soares; Alves, 2003, p. 16).

A atuação docente frente ao problema da pobreza é evidenciada em recente pesquisa avaliativa, desenvolvida pela United Nations Educational, Scientific and Cultural Organization (Unesco), sobre os programas sociais que vêm sendo implantados no Brasil. Essa pesquisa demonstra significativa redução da repetência e da evasão escolar, assim como melhoria da aprendizagem da população escolarizada das camadas mais pobres da sociedade.

São sinais positivos, mas não suficientes para tirar o País de sua condição de inferioridade educacional, visto que, de acordo com o Índice de Desenvolvimento da Educação Básica (Ideb) de $2005,{ }^{5}$ o quadro retratado pelos resultados das avaliações demonstra que a situação atual do ensino é dramática. Apenas um pequeno número de cidades (243), representando $5,58 \%$, conseguiu obter, nas duas etapas ( $1^{\text {a }}$ à $4^{\mathrm{a}}$ série e $5^{\mathrm{a}}$ à $8^{\mathrm{a}}$ série) do ensino fundamental oferecido pelas redes municipais, um Ideb igual ou superior a 5 . De $1^{\mathrm{a}}$ a $4^{\mathrm{a}}$ série das 4.349 cidades avaliadas, 4.112 obtiveram um índice inferior a 5, ou seja, uma taxa de 94,5\%.

$\mathrm{Na}$ fase de $5^{\mathrm{a}}$ a $8^{\mathrm{a}}$ série, o total de municípios com índice inferior a 5 foi de 2.453, entre os 2.467 avaliados - taxa de 99,4\%. Numa escala de 0 a 10, o Brasil obteve, em 2005, um Ideb médio de 3,8 na primeira fase do ensino fundamental ( $1^{\mathrm{a}}$ à $4^{\mathrm{a}}$ série), de 3,5 na segunda ( $5^{\mathrm{a}}$ à $8^{\mathrm{a}}$ série) e 3,4 no ensino médio.

Em 2007, segundo dados do Inep/Ideb, ${ }^{6}$ a alteração é insignificante diante dos dados de 2005, visto que em uma escala de 0 a 10, o Brasil tem hoje um Ideb médio de 4,2 nos anos iniciais do ensino fundamental, de 3,8 nos anos finais do ensino fundamental e 3,5 no ensino médio. Esse indicativo está aquém do Ideb de 6,0 pontos, considerado como média mínima para países desenvolvidos, e revela o quanto ainda teremos de avançar na perspectiva da ampliação de políticas e ações para o pleno desenvolvimento da educação brasileira. 
Em 2009, conforme dados do MEC/Inep, o Ideb sofre pequenas alterações, passando para 4,6 nos anos iniciais e 4,0 nos anos finais do ensino fundamental. O ensino médio, que tinha 3,5, passa para o índice de 3,6. Nesse contexto, foram avaliados 5.467 municípios, que incluem 44.765 escolas totalizando 2.559.566 alunos dos anos iniciais, 5.498 municípios, 32.901 escolas e 2.017.221 alunos dos anos finais do ensino fundamental. No período foram registradas 31.705 .528 matrículas no ensino fundamental e 8.337.160 no ensino médio. ${ }^{7}$

Os dados mostram que a crise do ensino é muito maior que a solução por cotas raciais, o que exige compromisso social, envolvendo Estado e sociedade, para um melhor desempenho da escola básica, de modo que o aluno possa galgar todos os níveis de ensino. A ideia é tratar da base e não do topo da pirâmide educacional, reproduzindo em nossos dias a drástica história da educação do Brasil, o que se evidencia em um modelo que priorizou a educação das elites, mediante níveis superiores, sobre a educação primária, nível este que atinge o povo em sua totalidade, independentemente de raça.

Um estudo completo sobre essa complexa questão não cabe no espaço deste artigo, mas fica em aberto a questão: de que qualidade de educação as escolas das classes menos favorecidas precisam para alunos que pouco trazem de vivências ricas e variadas, porque provenientes de famílias pobres? Que tipo de formação deveria ter o professor para lidar com crianças dessas classes, de modo a saber trabalhar com a diversidade manifestada na realidade de cada aluno? Que investimentos deveriam ser feitos para sanar definitivamente o analfabetismo que ainda persiste em nossa realidade? Seria esse o foco das verdadeiras ações afirmativas?

\section{Considerações finais}

Considerando a história da formação sociopolítica do Brasil e as condições de seu desenvolvimento, observa-se a formação de um país pobre, de maioria negra desde a colonização, sem muitas alterações desse quadro em nossos dias. Nesse prisma, deu-se a educação como um processo de exclusão da maioria pobre, em contraposição a um modelo educacional que favoreceu as elites econômicas desde a Colônia e se estendeu ao longo do Império e da República. As consequências disso são visíveis em nossa realidade nas altas taxas de analfabetismo, de reprovação, de evasão escolar, o que é evidenciado pela mídia a partir de levantamentos estatísticos do MEC e de organismos internacionais como a Unesco.

Nesse quadro, ações afirmativas para o ingresso no ensino superior, por questões raciais, parecem ser medidas que reproduzem a exclusão da maioria, constituindo-se medidas paliativas que servem, no máximo, para chamar a atenção dos brasileiros para o problema.

Na verdade, a solução da equidade e da qualidade em educação não reside em cotas, mas em maiores investimentos na educação, para a
7 Dados obtidos no site http:// portal.mec.gov.br/index.php?It emid $=86 \&$ id $=12221$ \&option $=\mathrm{C}$ om_content\&view=article 
garantia do acesso, da permanência e da qualidade, fundamentalmente na rede pública, no ensino fundamental e médio, além da criação de mais vagas nas universidades, para possibilitar aos negros, aos afrodescendentes, aos indígenas e aos brancos das classes pobres igualdade de condições para o acesso ao ensino superior.

É indispensável a criação de alternativas para a formação de jovens, de modo a tornarem-se cidadãos com possibilidades de ingressar no mundo do trabalho com a compreensão da realidade e a formação adequada; é necessário conhecimentos e não privilégios momentâneos que se esgotarão à medida que o aluno se depara com dificuldades técnicas e de manutenção, tais como compra de livros e de material necessário ao desenvolvimento de uma educação de qualidade, de modo a atender às exigências de uma sociedade altamente sofisticada em meios eletroeletrônicos que tal sistema não soluciona.

No entanto, em meio a tantas adversidades no contexto educacional brasileiro, algumas medidas estão sendo implementadas mediante ações do MEC voltadas para a diversidade. Cita-se a criação da Secretaria de Educação Continuada, Alfabetização e Diversidade (Secad) como um passo importante, porque ampliou o diálogo com a sociedade brasileira e possibilitou partir-se para ações que vão ao encontro de suas necessidades. Por sua vez, a posição do MEC, favorável aos recursos específicos para os alunos da área rural, quilombolas e indígenas, no Fundo da Educação Básica (Fundeb), é um reflexo desse diálogo. Entre as políticas da Secretaria de Educação Básica (SEB/MEC), o destaque é a formação inicial e continuada de professores, condição indispensável para melhorar a qualidade do ensino público.

Estas questões são notícias nos meios de comunicação diariamente:

O Brasil experimentou nos últimos anos um grande avanço na educação com a universalização do ensino fundamental e o acesso crescente ao ensino médio e superior. Mesmo sendo de baixa qualidade, o ensino básico pressiona os demais. A população brasileira de renda mais baixa despertou para a importância da educação como fator de redenção social. [...] O brasileiro pobre, que antes ficava restrito, se muito, aos quatro primeiros anos do antigo curso primário, exige, hoje, ingresso no ensino médio e já almeja chegar à universidade, mesmo que esta não seja gratuita (O Tempo, 2005).

Nessa ótica, o MEC criou a política de ingresso no ensino superior mediante o Programa Universidade para Todos (ProUni), que não deixa de ser um tipo de política afirmativa. Essas e outras iniciativas são louváveis como soluções emergenciais, mas nenhuma terá sucesso se as desigualdades sociais, tão acentuadas em nossa realidade, não forem levadas em consideração no processo educacional desde a base.

O que poderia provocar algumas alterações, de forma efetiva, seria favorecer o acesso à educação básica, pois não há ainda qualidade de ensino efetiva e claramente compreendida como necessária, o que nos remete à escola básica, a partir da educação infantil, na qual se situa a maior parte da população pobre do País. Pensar uma escola básica 
de qualidade consiste em transformar a escola do pobre em escola de formação de cidadãos aptos para assumir seus direitos e deveres na sociedade, tendo como premissa a recuperação da função social da escola. De nada adiantará pensar em ação afirmativa, se a escola do pobre continuar sendo uma escola pobre em condições físicas, em conhecimentos, em produção do conhecimento, em visão de mundo, com professores desprestigiados socialmente e despreparados para trabalhar com a pobreza. Ação afirmativa a partir da educação básica é lembrar que falta de dinheiro e diferença racial não são sinônimos de falta de inteligência. Nessa perspectiva, entende-se que oferecer condições educacionais para filhos de pobres e ricos igualmente, a partir da educação básica, pode significar a oportunidade de o País avançar efetivamente na questão cultural e de desenvolvimento social. Sem isso, toda e qualquer política educacional será inadequada.

A principal conclusão deste trabalho é, portanto, a consciência da importância de formulação e de implementação de políticas públicas educacionais, não só para a melhoria do desempenho escolar de uma forma geral, mas também para diminuir o impacto da origem socioeconômica no desempenho escolar, a partir da escola básica. Afinal, se a educação não é utilizada adequadamente para a inclusão, pode ser apenas um fator coadjuvante na reprodução das desigualdades.

\section{Referências bibliográficas}

BASBAUM, Leôncio. História sincera da República. Das origens a 1889. v. 1. 4. ed. São Paulo: Alfa Ômega, 1975.

BERGMANN, Barbara. In defense of affirmative action. New York: Basic Books, 1996.

BONFIM, Eduardo. Cultura, política e mitos do multiculturalismo.

Gazeta WEB, Maceió-AL, 7 de julho de 2007. Disponível em:

<www.universia.com.br/html/noticia>. Acesso em: 12 dez. 2009.

BORÓN, Atílio. Epílogo: ¿Una teoría social para el siglo XXI? Ponencia presentada em el XIV Congreso Mundial de la Asociación Internacional de Sociología. Montreal, Canadá, 1998. Disponível em: < http://campus. clacso.edu.ar >. Acesso em: 10 mar. 2010.

BRASIL. Constituição da República Federativa do Brasil, 1988.

Promulgada em 5 de outubro de 1988. São Paulo: Fisco e Contribuinte, 1988.

. Lei no 9.394, de 20 dezembro de 1996. Lei de Diretrizes e Bases da Educação Nacional. 
BRASIL. Ideb. Brasília-DF: Inep. Disponível em: < http://ideb.inep. gov. br/Site/>. Acesso em: 16 jun. 2008.

. MEC/CNE/CEB. Resolução no 7 de 14 de dezembro de 2010. Fixa as Diretrizes Curriculares Nacionais para o Ensino Fundamental de 9 (nove) anos.

CRESPO, Antônio Pedro Albernaz; GUROVITZ, Elaine. A pobreza como um fenômeno multidimensional. RAE-Eletrônica, v. 1, n. 2, jul./dez., 2002. Disponível em: < http://www.rae.com.br/eletronica/index.cfm?Fu seAction $=$ Artigo \&ID $=1178 \&$ Secao $=$ PÚBLICA\&Volume $=1 \&$ Numero $=2 \&$ Ano $=2002>$. Acesso em: 15/1/2010.

DRIVER, Stephanie Schwartz. A Declaração de Independência dos Estados Unidos. São Paulo. Jorge Zahar, 2006.

ESTRONIOLI, Elisa. Cresce proporção de pardos e pretos no país; brancos, amarelos e indígenas perdem espaço. UOL Notícias. Disponível em: <http://noticias.uol.com.br/especiais/pnad/2010/ ultimas-noticias/2010/09/08/cresce-proporcao-de-pardos-e-pretos-nopais-brancos-amarelos-e-indigenas-perdem-espaco.jhtm > . Acesso em: 5 jan. 2011.

IPEA. Assessoria da Presidência. Pobreza e riqueza no Brasil metropolitano. Disponível em: <http://www.ipea.gov.br/sites/000/2/ destaque/estudoVF2.pdf>. Acesso em: 13 nov. 2010.

KAUFMANN, Roberta Fragoso Menezes. Pobreza não tem raça. Revista Consultor Jurídico, 2007. Disponível em: <www.conjur.com.br>. Acesso em: 12 nov. 2010.

Ações Afirmativas à brasileira: necessidade ou mito? Uma análise histórico-jurídico-comparativa do negro nos Estados Unidos da América e no Brasil. Porto Alegre: Livraria dos Advogados, 2007.

LUCCI, Elian Alabi. O verdadeiro sentido da pobreza. Diário da Região, São José do Rio Preto-SP, março de 2003.

MARTINS, Ives Gandra da Silva. Terra de privilégios. Gazeta Mercantil, São Paulo, 6 de fevereiro de 2008.

MOTA, Carlos Guilherme; NOVAIS, Fernando. Independência política do Brasil. São Paulo: Hucitec, 1996.

PASTORE, José; ZYLBERSTAJN, Hélio; PAGOTTO, Carmen Silva. Mudança social e pobreza no Brasil: 1970-1980. São Paulo: Livraria Pioneira, 1983. 
POBREZA e educação. O tempo, 2 de dezembro de 2005. Disponível em: <www.universia.com.br/html/noticia> . Acesso em: 15 mar. 2009.

SALLES, Silvana. Mapa da pobreza mudou pouco em dez anos. UOL Notícias, São Paulo, 2008. Disponível em: < http://noticias.uol.com. br/cotidiano/2008/09/09/ult5772u771.jhtm>. Acesso em: 15 jan. 2011.

SHAKTI, Deva. Dalits. A difícil vida dos dalits na Índia. Postado em 4 de fevereiro de 2009. Disponível em: < http://deva-dani.blogspot. com/2009/02/dalits.html>. Acesso em: 13 out. 2010.

SCHWARTZMAN, Simon. O populismo universitário. Jornal do Brasil, Rio de Janeiro, 8 de julho de 1987. Disponível em: < http://www. schwartzman.org.br/simon/boi.htm Acesso em: 13/10/2010>.

As causas da pobreza. Rio de Janeiro: Fundação Getúlio Vargas, 2004.

SILVA, Alexandre Vitorino. O desafio das ações afirmativas no direito brasileiro. Jus Navigandi, Teresina-PI, a. 7, n. 60, nov. 2002. Disponível em: <http://www1.jus.com.br/doutrina/texto.asp?id=3479>. Acesso em: 24 maio 2008.

SOARES, José Francisco; ALVES Maria Tereza G. Desigualdades raciais no sistema brasileiro de educação básica. Educação e Pesquisa, São Paulo, v. 29, n. 1, p. 1-23, jan./jun., 2003.

SODRÉ, Nelson Werneck. Síntese da história da cultura brasileira. 5. ed. Rio de Janeiro: Civilização Brasileira, 1977.

TRAGTENBERG, Marcelo Henrique Romano. Um olhar branco sobre ações afirmativas. Revista Espaço Acadêmico, Maringá: UEM, a. II, n. 13, jun. 2002. Disponível em: <www.espacoacademico.com.br>. Acesso em: 10 nov. 2009.

UNESCO. Relatório da $3^{a}$ Conferência Internacional de Combate ao Racismo, Discriminação Racial, Xenofobia e Formas Correlatas de Intolerância, realizada em Durban, 2001. Disponível em: < http://www. comitepaz.org.br/Durban_1.htm>. Acesso em: 15 jan. 2011.

WEDDERBURN, Carlos Moore. Do marco histórico das políticas públicas de ações afirmativas - perspectivas e considerações. In: SANTOS, Sales Augusto dos (Org.). Ações afirmativas e combate ao racismo nas Américas. Brasília: Ministério da Educação/Secretaria de Educação Continuada, Alfabetização e Diversidade, 2005. 
WEIDEN, Fernanda Giroleti. O que são ações afirmativas? Disponível em: <http://listas.softwarelivre.org/pipermail/psl-mulheres/ 2005-July/001340.html> . Acesso em: 17 maio 2008.

WERTHEIN, Jorge. Pobreza e educação: rompendo o círculo vicioso. O Globo, Rio de Janeiro, 10 de julho de 1998; Diário de Pernambuco, Recife, 15 julho de 1998; A Gazeta, Vitória, 16 de julho de 1998; O Popular, Goiânia, 16 de julho de1998.

Sueli Menezes Pereira, doutora em Educação pela Universidade Estadual de Campinas (Unicamp), é professora no Programa de PósGraduação em Educação na Universidade Federal de Santa Maria (UFSM). sueli@ce.ufsm.br

Clarice Zientarski, doutoranda em Educação pela Universidade Federal de Santa Maria (UFSM), é professora de Educação Básica em escola pública. claricezientarski@yahoo.com.br

Recebido em 10 de abril de 2011.

Aprovado em 29 de setembro de 2011. 